Article

\title{
Synthesis and Characterization of Activated Carbon Fibers Derived from Linear Low-Density Polyethylene Fibers Stabilized at a Low Temperature
}

\author{
Kwan-Woo Kim ${ }^{1}$, Hye-Min Lee ${ }^{1}$, Seong-Hyun Kang ${ }^{1,2}$ and Byung-Joo Kim ${ }^{3, *(D)}$ \\ 1 R\&D Office 1st, Korea Carbon Industry Promotion Agency, Jeonju 54852, Korea; \\ 01090063344@kcarbon.or.kr (K.-W.K.); leehm@kcarbon.or.kr (H.-M.L.); ksh8406@kcarbon.or.kr (S.-H.K.) \\ 2 Department of Organic Materials \& Fiber Engineering, Jeonbuk National University, Jeonju 54896, Korea \\ 3 Department of Carbon-Nanomaterials Engineering, Jeonju University, Jeonju 55069, Korea \\ * Correspondence: kimbyungjoo@jj.ac.kr
}

Citation: Kim, K.-W.; Lee, H.-M.; Kang, S.-H.; Kim, B.-J. Synthesis and Characterization of Activated Carbon Fibers Derived from Linear Low-Density Polyethylene Fibers Stabilized at a Low Temperature. Polymers 2021, 13, 3918. https:// doi.org/10.3390/polym13223918

Academic Editor: Daniela Suteu

Received: 15 October 2021

Accepted: 5 November 2021

Published: 12 November 2021

Publisher's Note: MDPI stays neutral with regard to jurisdictional claims in published maps and institutional affiliations.

Copyright: (c) 2021 by the authors. Licensee MDPI, Basel, Switzerland. This article is an open access article distributed under the terms and conditions of the Creative Commons Attribution (CC BY) license (https:/ / creativecommons.org/licenses/by/ $4.0 /)$.

\begin{abstract}
In this study, activated carbon fibers (ACFs) were prepared using a new method from polyethylene (PE) fibers. The stabilizing (or crosslinking) process of PE, an essential step, was achieved through a hybrid treatment using electron-beam/sulfuric acid at $110^{\circ} \mathrm{C}$ that was more effective than the traditional method of using sulfuric acid at $180^{\circ} \mathrm{C}$ for polyolefin. The stabilized precursor was then carbonized at $700{ }^{\circ} \mathrm{C}$ and activated at $900{ }^{\circ} \mathrm{C}$ with different activation times. The structural characteristics and morphologies of these ACFs were observed using an X-ray diffractometer and a field-emission scanning electron microscope, respectively. In addition, the $\mathrm{N}_{2} / 77 \mathrm{~K}$ adsorption isotherm was used to discern textural properties. The total pore volume and specific surface area of these ACFs were found to be increased with a longer activation time, reaching final values of $0.99 \mathrm{~cm}^{3} / \mathrm{g}$ and $1750 \mathrm{~m}^{2} / \mathrm{g}$, respectively. These ACFs also exhibited a high mesopore volume ratio (39\%) according to crosslinking and crystallite formation conditions.
\end{abstract}

Keywords: carbon fibers; recycling; upcycling; recovery; carbon fibers reinforced plastics

\section{Introduction}

Activated carbon fibers are generally manufactured using the same precursors as carbon fibers, such as synthetic polymers [1-3], petroleum-based pitch [1,4], and natural cellulose [1,5]. Specifically, activated carbon fibers are prepared through the stabilization, carbonization, and activation of precursor fibers. The activation can be achieved either by physical or chemical methods [6-9]. Physical methods use steam or carbon dioxide as an activation agent. They can be applied to most activated carbon fiber manufacturing processes because the process cost is low [10].

Activated carbon fibers have a high specific surface area and a well-developed pore structure. Therefore, they are widely used as environmental adsorption and energy storage materials [11-13]. However, since manufacturing activated carbon fibers requires many steps and high oxidation conditions, it usually entails a high cost. Thus, many studies have been conducted to find lower-cost manufacturing methods. The most common technique to produce activated carbon fibers is using new precursors [14-16].

Recently, carbon fiber has been produced using polyethylene, which is a relatively inexpensive material. Although carbon fibers produced with polyethylene have lower mechanical strengths than commercial carbon fibers, they show the possibility to manufacture carbon fibers using thermoplastic polyethylene [17]. To impart thermal stability to thermoplastic polyethylene, most studies have used sulfuric acid treatment at $180{ }^{\circ} \mathrm{C}$ or higher. However, since it is difficult to control the crosslinking rate at such high temperatures, precursor fibers are easily broken, making it challenging to develop a continuous process [18]. For that reason, polyethylene can be utilized as an optimal precursor for 
producing activated carbon fibers because thermal stability can be achieved using sulfuric acid at a lower temperature.

Typical well-known crosslinking methods for polyethylene include electron beam radiation [19], peroxide [20], silane coupling agents [21], and sulfuric acid treatment [22]. Sulfuric acid treatment can induce the highest crosslinking density, resulting in a high carbonization yield [18]. The crosslinking method using peroxide and silane coupling agents is unsuitable for crosslinking polyethylene fibers because it is performed on the surface with a limited depth of crosslinking [23]. However, irradiation of high-energy electrons can lead to sufficient crosslinking even with a fibrous precursor. In addition, electron beam treatment can easily implant radicals in the polyethylene chain structure [24]. When an electron beam and sulfuric acid treatment are applied together to polyethylene fibers, the electron beam can lead to the pre-curing of polyethylene chains. In addition, generated radicals can accelerate sulfuric acid crosslinking at a relatively low temperature [25].

In this study, we manufactured activated carbon fibers using a polyethylene precursor stabilized at a low temperature through electron beam irradiation and sulfuric acid complex treatment. We also determined the pore structure development in activated carbon fibers using different manufacturing conditions.

\section{Experiment Details}

\subsection{Materials and Methods}

Linear low-density polyethylene (LLDPE, LG Chem., Seoul, Korea) and concentrated sulfuric acid $\left(\mathrm{H}_{2} \mathrm{SO}_{4}\right.$, Daejung Chem., Siheung, Korea) were used in the experiment. First, an electron beam was stably irradiated on a flat stainless-steel plate $\left(50 \times 50 \mathrm{~cm}^{2}\right)$. LLDPE fibers were placed on the plate, with both ends of the fiber fixed. Subsequently, the plate was irradiated using a $1.5 \mathrm{MeV}$ accelerator (ELV-12, EB TECH Co. LTD., Daejeon, Korea) with a constant plate speed of $10 \mathrm{~m} / \mathrm{min}$. When passed once through the accelerator, the dose was ten kGy. The total dose was controlled at 1000 to $2000 \mathrm{kGy}$. The second crosslinking of LLDPE was carried out in hot sulfuric acid. A concentrated sulfuric acid $(98 \%)$ was heated to a temperature of $110^{\circ} \mathrm{C}$. After treatments for a predetermined length of temperature and time, the LLDPE was taken out, washed thoroughly in distilled water, and dried in a drying oven at $60^{\circ} \mathrm{C}$ for $24 \mathrm{~h}$. The reaction mechanism of the hybrid crosslinking with LLDPE is illustrated in Figure 1.

These crosslinked LLDPE fibers were set on an alumina plate which was then inserted into a self-tuning alumina tubular furnace (length $1000 \mathrm{~mm}$, SiC heater, diameter $100 \mathrm{~mm}$, TENG, Jeonju, Korea). The crosslinked fibers were heated up to $900{ }^{\circ} \mathrm{C}$ at a temperature rise rate of $10^{\circ} \mathrm{C} / \mathrm{min}$ under a nitrogen gas flow and held at the carbonization temperature for one hour. The carbonization yield of the carbonized LLDPE fibers was found to be about $58.3 \%$. The gas flow was then switched to $\mathrm{H}_{2} \mathrm{O}$ at a $0.5 \mathrm{~mL} / \mathrm{min}$ rate and held for 20 to $40 \mathrm{~min}$. The PE-ACF was then cooled under $\mathrm{N}_{2}$ gas at a flow rate of $300 \mathrm{~mL} / \mathrm{min}$ [14].

The samples according to preparation conditions are listed in Table 1.

Table 1. Sample names according to crosslinking and activation conditions.

\begin{tabular}{|c|c|c|c|c|c|c|c|}
\hline \multirow{2}{*}{$\begin{array}{l}\text { Sample } \\
\text { Name }\end{array}$} & \multicolumn{4}{|c|}{ Crosslinking Conditions } & \multirow{2}{*}{$\begin{array}{l}\text { Sample } \\
\text { Name }\end{array}$} & \multicolumn{2}{|c|}{ Activation Conditions } \\
\hline & & & Su & Acid & & Temp. & Time \\
\hline $\begin{array}{l}\text { PE-E-10-S-3 } \\
\text { PE-E-10-S-6 }\end{array}$ & \multirow{3}{*}{$1.5 \mathrm{MeV}$} & 1000 kGy & \multirow{3}{*}{$110^{\circ} \mathrm{C}$} & \multirow{3}{*}{$30,60 \mathrm{~min}$} & - & - & - \\
\hline $\begin{array}{l}\text { PE-E-15-S-3 } \\
\text { PE-E-15-S-6 }\end{array}$ & & 1500 kGy & & & $\begin{array}{l}\text { ACF-9-2 * } \\
\text { ACF-9-3 * } \\
\text { ACF-9-4 * }\end{array}$ & $900^{\circ} \mathrm{C}$ & 20 to $40 \mathrm{~min}$ \\
\hline $\begin{array}{l}\text { PE-E-20-S-3 } \\
\text { PE-E-20-S-6 }\end{array}$ & & 2000 kGy & & & - & - & - \\
\hline
\end{tabular}

* This sample was prepared using the PE-E-15-S-6 sample. 


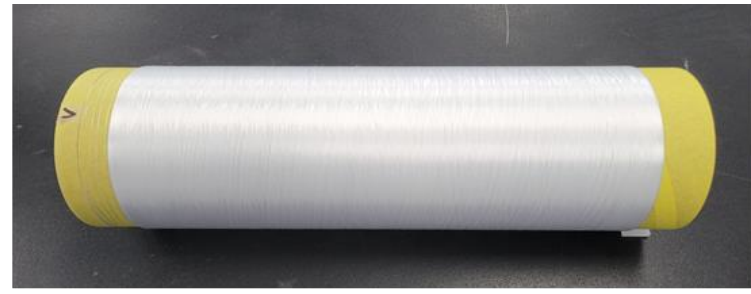

\section{LLDPE fibers}
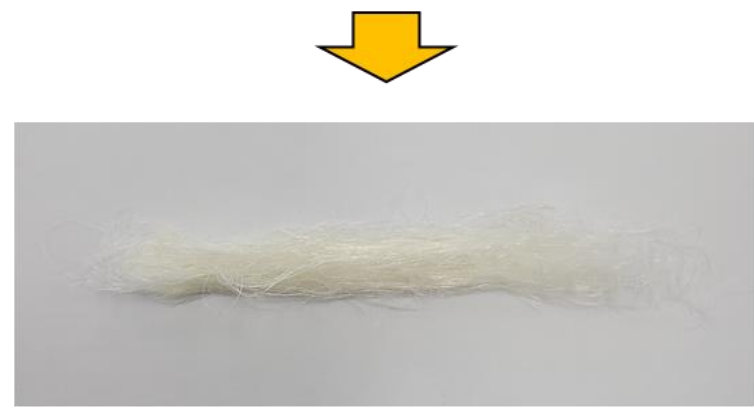

\section{E-beam treated fibers}
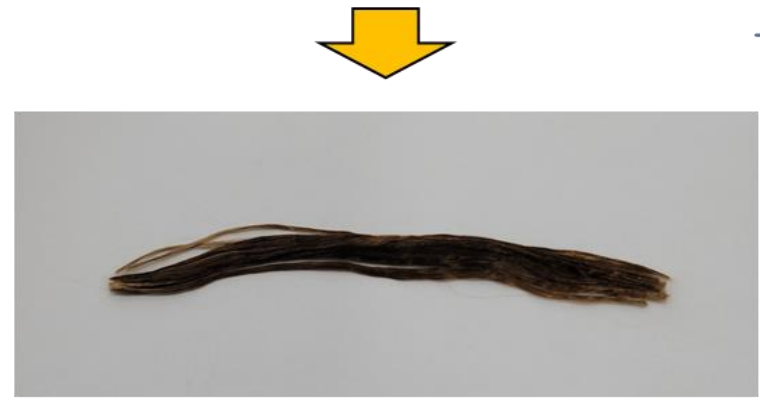

(E-beam + Sulfuric acid) treated fibers
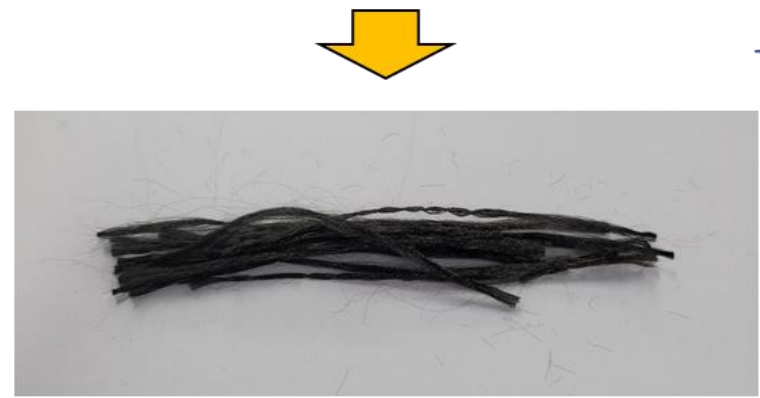

\section{PE-based activated carbon fibers}

\{

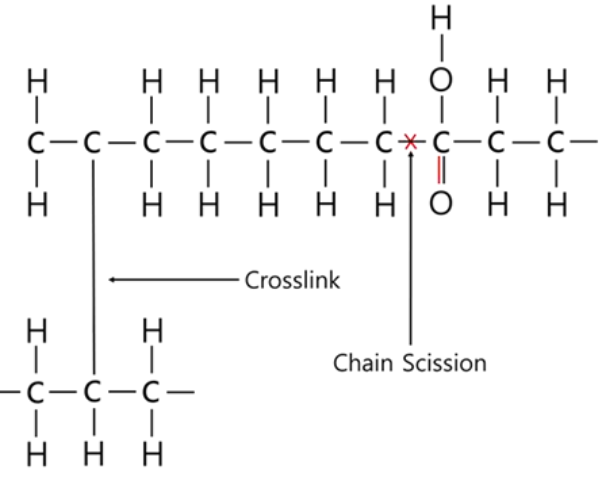

\{<smiles>C=C/C(O)=C/C=C(O)/C=C/C=C/C(O)=C/C</smiles>

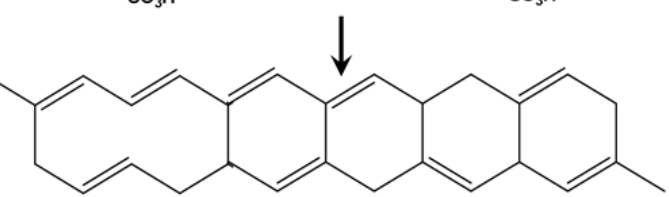

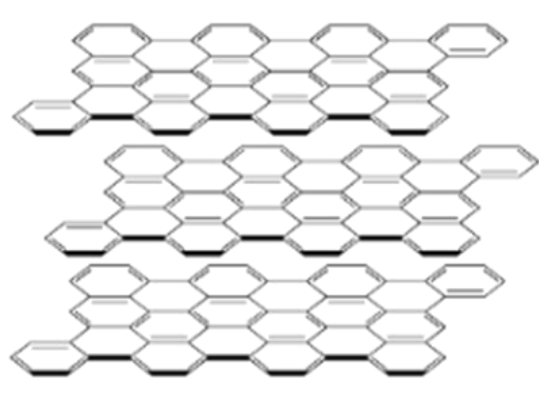

Figure 1. Manufacturing process of linear low-density polyethylene (LLDPE) based activated carbon fibers.

\subsection{Characterizations}

The effects of the crosslinking temperature on the characteristics of the samples were researched using thermal analyses such as thermogravimetric analysis (SHIMADZU, Kyoto, Japan) and differential scanning calorimetry (SHIMADZU, Kyoto, Japan). DSC analysis was performed at a heating and cooling rate of $10^{\circ} \mathrm{C} / \mathrm{min}$ with a temperature range of 30 to $300{ }^{\circ} \mathrm{C}$. The sample was purged with nitrogen gas at a $10 \mathrm{~mL} / \mathrm{min}$ flow rate to maintain an inert environment. TGA analysis was performed for all samples under a pure nitrogen atmosphere. All samples were heated from $30^{\circ} \mathrm{C}$ up to $900{ }^{\circ} \mathrm{C}$ at a temperature rise rate of $10^{\circ} \mathrm{C} / \mathrm{min}$.

Differences in the microstructure of the sample at each preparation step (E-beam treatment, carbonization, and activation steps) were determined using a X-ray diffractometer (PANalytical, Malvern, England) with an EMPYREAN X-ray diffractor having a 
customized auto-mount and a $\mathrm{Cu} \mathrm{K}($ alpha) radiation source at $30 \mathrm{~mA}$ and $40 \mathrm{kV}$. Diffraction patterns were investigated within diffraction angles from $10^{\circ}$ to $90^{\circ}$ at a speed of $2 \circ / \mathrm{min}$. Morphologies of hybrid-treated PE fibers and their ACFs were explored with scanning electron microscopy (SEM, AIS 2000C, Seron Tech Inc., Uiwang, Korea). To reduce charging during scanning electron microscopy imaging, samples were first placed on a sample holding plate and coated with platinum. When measuring, the pressure of the analyzer chamber was about $5 \times 10^{-5} \mathrm{~Pa}$, and the acceleration voltage was $20 \mathrm{kV}$.

The nitrogen adsorption isotherms of ACFs were measured with a BELSORP-Max (BEL Japan, Tokyo, Japan) at $-196{ }^{\circ} \mathrm{C}$ (liquid nitrogen temperature). All samples were degassed for approximately $6 \mathrm{~h}$ at $301{ }^{\circ} \mathrm{C}$, with the degassing pressure maintained at $0.1 \mathrm{~Pa}$ or less. The specific surface area was secured using the Brunauer-Emmett-Teller (BET) method [26]. Micropore and mesopore size distributions were estimated via the nonlocal density functional theory (NLDFT) [27] and the Barrett-Joyner-Halenda (BJH) [28] method, respectively.

A continuous flow column reactor (quartz column) was used to measure the acetaldehyde adsorption capacity of the PE-ACFs. Each ACF $(0.5 \mathrm{~g})$ was packed into the column (with a length of $700 \mathrm{~mm}$ and an inner diameter of $12.7 \mathrm{~mm}$ ). The acetaldehyde (a flow rate of $2.0 \mathrm{~L} / \mathrm{min}$ and a concentration of $10 \mu \mathrm{g} / \mathrm{mL}$ ) was fed into the column. A gas detecting tube (92L, Gastech, Ayase-Shi, Japan) was used to monitor the concentrations of acetaldehyde at the outlet of the adsorption column.

\section{Results and Discussion}

\subsection{Primary Crosslinking of Precursor Fibers}

The change in the calorific value of crosslinked LLDPE fibers according to the E-beam irradiation was measured by differential scanning calorimetry (DSC). The results are shown in Figure 2. It was confirmed that as the E-beam irradiation increased, the endothermic and exothermic values of the PE samples decreased. E-beam irradiation is known to induce crosslinking between PE chains and the rupture of $\mathrm{C}-\mathrm{C}$ bonds. When the crosslinking between PE chains increases, the quantity of heat absorption required for melting and heat radiation by recrystallization will decrease. The results of this experiment were consistent with this theory.

In addition, it was confirmed that the maximum temperatures of $T_{m}$ and $T_{c}$ were reduced, indicating that samples were thermally unstable due to the rupture of $\mathrm{C}-\mathrm{C}$ bonds in uncrosslinked chains caused by the E-beam irradiation as described above. Thus, melting and crystallization proceeded at a relatively lower temperature compared to the as-received PE.

Differences in the microcrystalline structure of the PE fiber after different amounts of E-beam irradiation were observed through X-ray diffraction (XRD) analysis. The results are shown in Figure 3 and Table 2. As the E-beam irradiation increased to $1500 \mathrm{kGy}$, the crystallite size decreased. It rose again when the dose of irradiation was increased to $2000 \mathrm{kGy}$. It was presumed that the E-beam treatment induced crosslinking of the LLDPE molecular chain and caused the destruction of $\mathrm{C}-\mathrm{H}$ and $\mathrm{C}-\mathrm{C}$ bonds at the same time, resulting in a change of the crystallite size. When the irradiation dose was increased up to $1500 \mathrm{kGy}$, the average crystallite size was decreased in XRD because both crosslinking and the breaking of bonds occurred. When the irradiation dose was increased to $2000 \mathrm{kGy}$, which could be considered an excessive treatment, fine crystallites were mainly destroyed, and the average crystallite size was increased. These phenomena were considered to be related to decreases in $T_{m}$ and $T_{c}$ temperatures based on DSC results that occurred for the same reasons (i.e., crosslinking of the LLDPE molecular chain and destruction of C-H and C-C bonds). 


\subsection{Second Crosslinking in Sulfuric Acid}

As a second crosslinking step, pre-crosslinked LLDPE precursor fibers were treated in sulfuric acid for a different time period. DSC and TGA analyses were then performed for each sample after the second treatment. The results are shown in Figures 4 and 5, respectively.
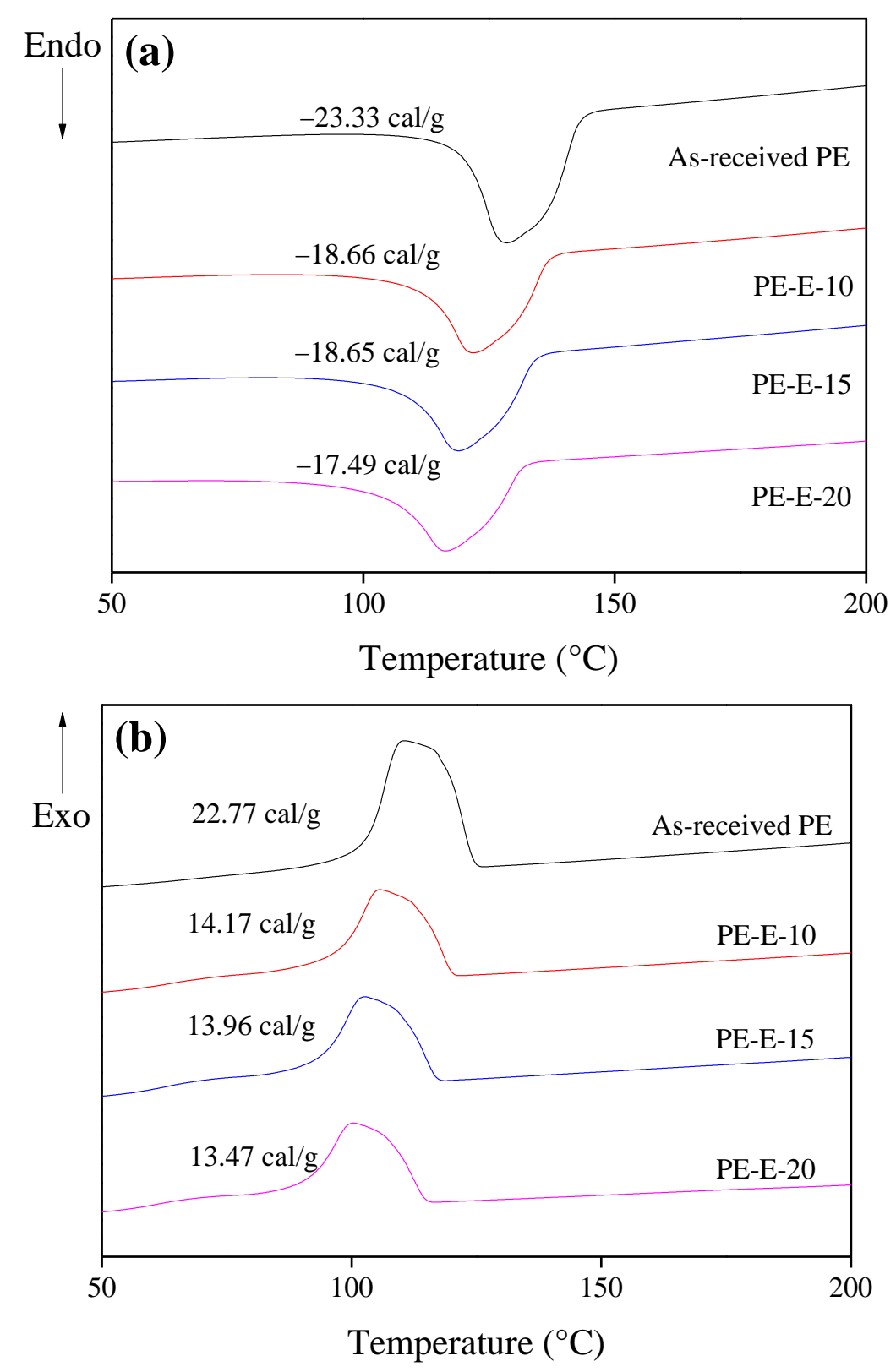

Figure 2. Differential scanning calorimetry (DSC) graphs of as-received LLDPE fibers and E-beamtreated fibers: (a) heating, (b) cooling.

Table 2. XRD result of as-received LLDPE fibers and E-beam-treated fibers.

\begin{tabular}{ccccccccc}
\hline & \multicolumn{4}{c}{$\mathbf{1 1 0}$ Peak } \\
\cline { 2 - 9 } $\begin{array}{c}\text { Sample } \\
\text { Name }\end{array}$ & $\mathbf{2 \theta}$ & $\begin{array}{c}\text { FWHM } \\
\mathbf{( 2 \theta )}\end{array}$ & $\mathbf{d}_{\mathbf{1 1 0}}(\mathbf{\AA})$ & $\mathbf{L}_{\mathbf{1 1 0}}(\AA)$ & $\mathbf{2 \theta}$ & $\begin{array}{c}\text { FWHM } \\
\mathbf{( 2 \theta )}\end{array}$ & $\mathbf{d}_{\mathbf{2 0 0}}(\AA)$ & $\mathbf{L}_{\mathbf{2 0 0}}(\AA)$ \\
\hline As-received & 21.70 & 0.59 & 4.09 & 136.46 & 24.03 & 0.70 & 3.70 & 116.12 \\
PE-E-10 & 21.69 & 0.71 & 4.09 & 114.06 & 24.02 & 0.81 & 3.70 & 99.94 \\
PE-E-15 & 21.57 & 0.78 & 4.12 & 103.74 & 23.88 & 0.88 & 3.72 & 92.13 \\
PE-E-20 & 21.60 & 0.65 & 4.11 & 125.16 & 23.90 & 0.76 & 3.72 & 107.54 \\
\hline
\end{tabular}




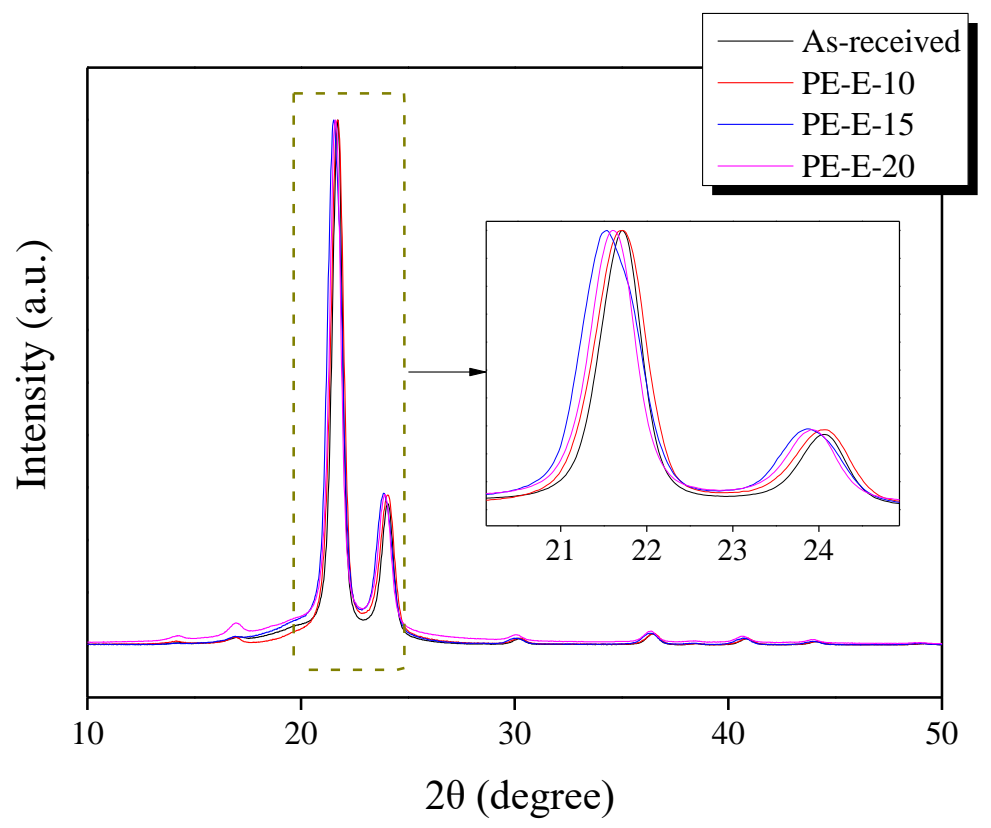

Figure 3. X-ray diffraction (XRD) patterns of as-received LLDPE fibers and E-beam crosslinked LLDPE fibers.
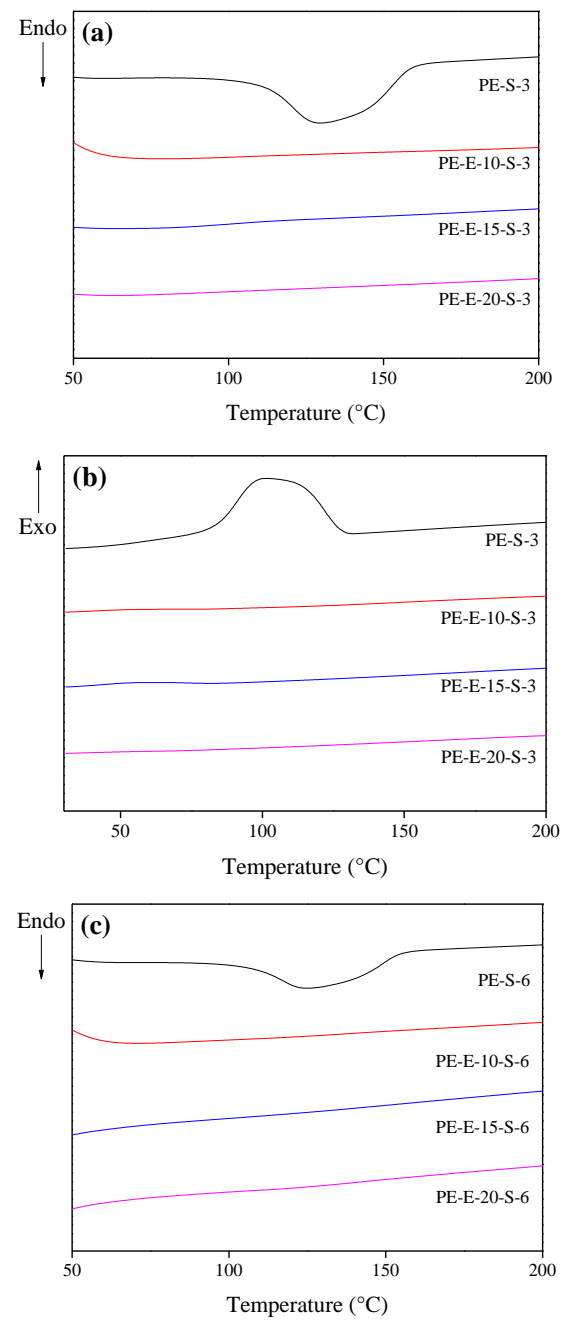

Figure 4. Cont. 


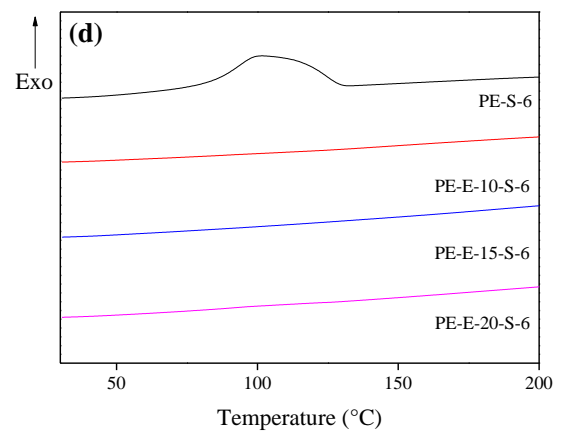

Figure 4. DSC graphs of E-beam- and sulfuric acid-treated LLDPE fibers: (a,b), sulfuric acid $30 \mathrm{~min}$, (c,d), sulfuric acid $60 \mathrm{~min}$.
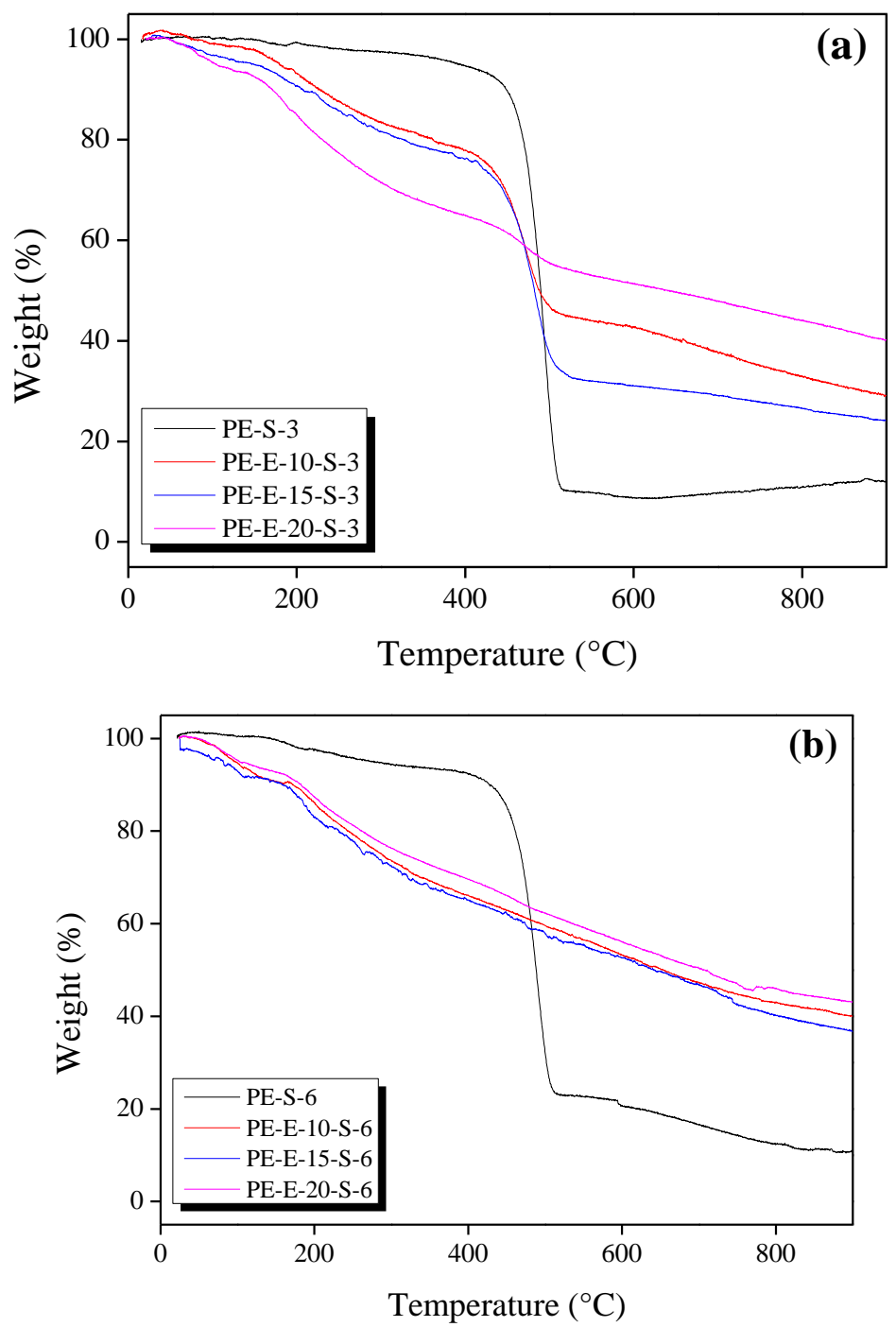

Figure 5. TGA graphs of E-beam and sulfuric acid treated LLDPE fibers: (a) sulfuric acid $30 \mathrm{~min}$, (b) sulfuric acid $60 \mathrm{~min}$.

The secondary crosslinking was carried out by treating the first-treated precursor fibers in an undiluted sulfuric acid at $110{ }^{\circ} \mathrm{C}$ for $30 \mathrm{~min}$ or more. At this time, both ends of the fibers were fixed to minimize shape change (longitudinal direction) due to shrinkage. The DSC analysis showed that none of the secondary-treated samples exhibited endothermic or heat radiation behaviors required for melting and recrystallization. This 
meant that no molecular structure exhibiting thermoplastic behavior remained after the secondary treatment. Therefore, complete crosslinking or cyclization had occurred.

Figure 5 shows the results of the TGA analysis of the E-beam/Sulfuric acid hybridtreated samples and the simple sulfuric acid-treated sample (comparative specimen). The most significant difference between the hybrid-treated samples and the comparative specimen was the thermal decomposition initiation temperature. The comparative sample exhibited a slight decrease in mass up to $450^{\circ} \mathrm{C}$, followed by a rapid decrease in mass, resulting in a final yield of about $10 \%\left(800{ }^{\circ} \mathrm{C}\right)$. On the other hand, all hybrid-treated samples steadily decreased in mass up to $800{ }^{\circ} \mathrm{C}$ (around $40 \%$ loss), reaching a final yield of about $45 \%\left(800{ }^{\circ} \mathrm{C}\right)$. The more significant initial decrease in mass exhibited by hybrid-treated samples as compared to the comparative sample was, therefore, determined to be due to the E-beam treatment. As noted previously, the E-beam treatment simultaneously induced crosslinking between PE molecular chains and ruptured $\mathrm{C}-\mathrm{C}$ bonds, thus producing molecular structures with a low molecular weight and low thermal stability.

However, there was still a marked difference in weight between samples treated for $30 \mathrm{~min}$ and those treated for $60 \mathrm{~min}$. In samples treated for $30 \mathrm{~min}$, the initial mass loss was significant, and the final yield increased as the E-beam irradiation increased. This meant that dual effects of E-beam irradiation (molecular chain crosslinking and molecular chain cutting) occurred in proportion to its dose. All samples treated for 60 min exhibited similar TGA curves regardless of the E-beam irradiation dose. This meant that $60 \mathrm{~min}$ of sulfuric acid treatment was enough for complete crosslinking to occur.

\subsection{Microstructure, Optic Image, and Morphology of Activated Carbon Fibers}

$\mathrm{X}$-ray diffraction $(\mathrm{XRD})$ is one of the methods that can efficiently analyze changes in the microcrystalline structure of carbon materials. Among hybrid-treated PE fibers, PEE-15-S-30 and PE-E-15-S-60 samples were chosen to be carbonized at $900{ }^{\circ} \mathrm{C}$ in a nitrogen atmosphere. The carbonized PE-E-15-S-60 sample was then selected to be activated at $900{ }^{\circ} \mathrm{C}$ in a steam atmosphere for various time durations. The XRD patterns and calculated values for the two carbonized samples and the one activated sample (ACF-9-2) are depicted in Figure 6 and Table 3, respectively.

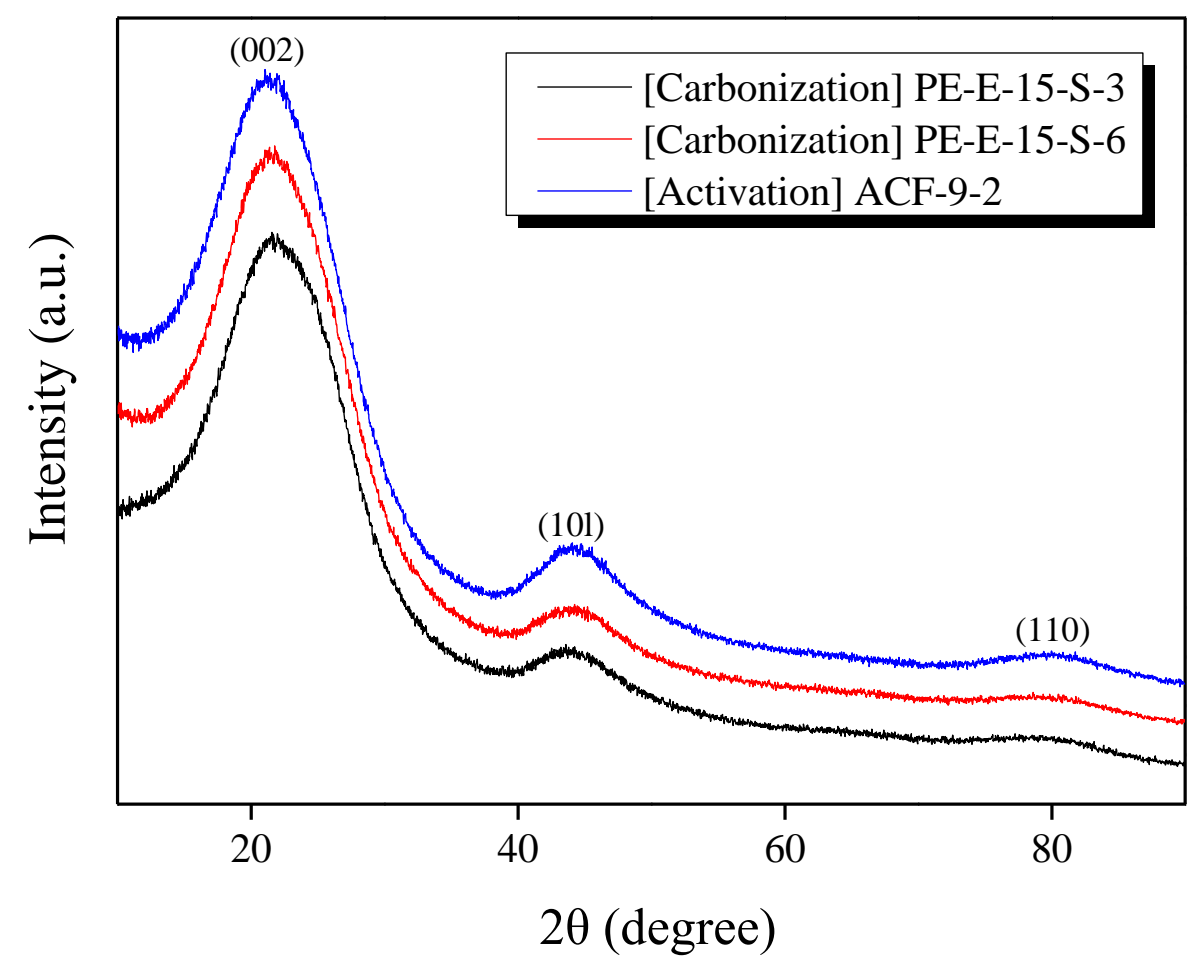

Figure 6. XRD patterns of hybrid-treated LLDPE fibers after carbonization $\left(900^{\circ} \mathrm{C}\right)$ and activation. 
Table 3. XRD patterns of hybrid crosslinked LLDPE fibers after carbonization and activation.

\begin{tabular}{lcccccccc}
\hline \multirow{2}{*}{ Step } & \multirow{2}{*}{ Sample Name } & \multicolumn{3}{c}{ 002 Peak } & \multicolumn{3}{c}{ 101 Peak } \\
\cline { 3 - 8 } & & $\mathbf{2 \theta}$ & $\mathbf{d}_{\mathbf{0 0 2}}(\AA)$ & $\mathbf{L}_{\mathbf{c}}(\AA)$ & $\mathbf{2 \theta}$ & $\mathbf{d}_{\mathbf{1 0 1}}(\AA)$ & $\mathbf{L}_{\mathbf{a}}(\AA)$ \\
\hline \multirow{2}{*}{ Carbonization } & PE-E-15-S-3 & 22.46 & 3.96 & 9.04 & 44.33 & 2.04 & 17.76 \\
& PE-E-15-S-6 & 22.34 & 3.98 & 9.25 & 44.52 & 2.03 & 17.48 \\
\hline \multirow{2}{*}{ Activation } & ACF-9-2 & 22.50 & 3.95 & 9.70 & 44.80 & 2.02 & 30.40 \\
\hline
\end{tabular}

In the XRD pattern, typical 002 and 101 peaks of carbon materials were clearly observed for all samples. Both $\mathrm{L}_{\mathrm{c}}$ (crystallite height) and $\mathrm{L}_{\mathrm{a}}$ (crystallite size) increased significantly after carbonization and activation. This effect was due to the growth of crystallites themselves during the carbonization and activation process. It was also due to the fact that relatively small crystallites were preferentially oxidized. Thus, the average size was observed as increasing. Specifically, activation is a reaction of oxidizing graphitic crystallites of a carbonized precursor. It is widely known that oxidization occurs from amorphous domains of the precursor. In the activation process, carbonaceous precursors are oxidized in a particular order: first amorphous domains, then small crystallites, and then the edges of large crystallites. However, the $\mathrm{L}_{\mathrm{a}}$ and $\mathrm{L}_{\mathrm{c}}$ values calculated from XRD only conveyed the average values of all crystallites. Therefore, the increase in $L_{a}$ was considered a relative increase due to the oxidation of amorphous domains or relatively small crystallites, and the increase in $\mathrm{L}_{c}$ was believed to be due to the oxidation of relatively small crystallites with few graphitic layers.

The optic and SEM images of the final activated carbon fibers (ACFs) are shown in Figure 7. The ACF-9-2 sample fiber maintained a hair-like shape. It was determined to have a strength of more than $13.6 \mathrm{MPa}$ as it did not break even when $70 \mathrm{mg}$ of the peg was attached to one ACF strand (average diameter of $8 \mathrm{um}$ ). The cross-section of each activated carbon fiber was observed in a circular shape through the SEM images. No damage was observed on the fiber surface. This was believed to be due to the very dense internal crosslinking through hybrid treatments.

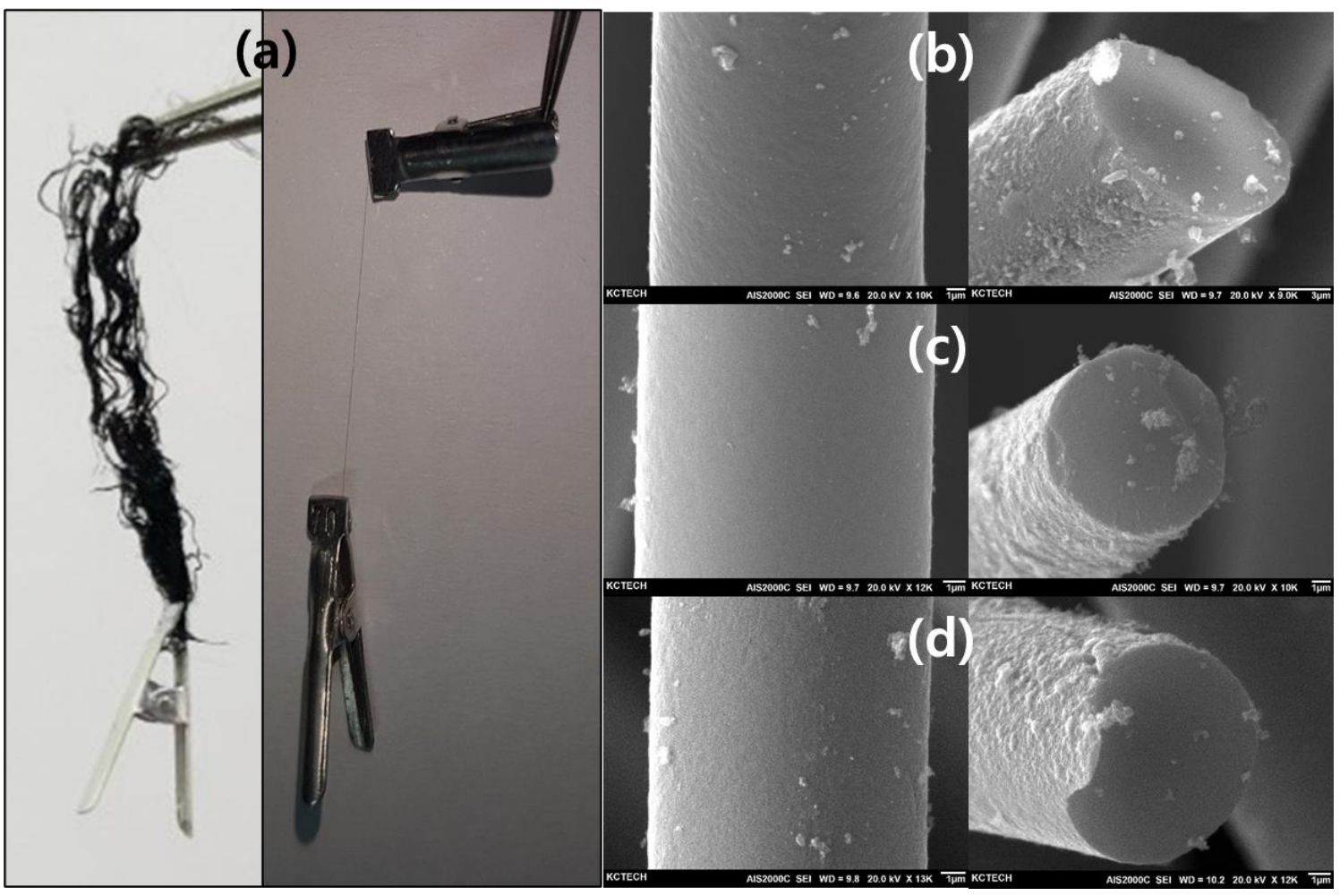

Figure 7. Optic and SEM images of activated carbon fibers: (a,b) ACF-9-2, (c) ACF-9-3, (d) ACF-9-4. 


\subsection{Pore Characteristics of LLDPE-Based Activated Carbon Fibers}

To analyze textural properties including the specific surface area, total pore volumes, and micropore volumes of the prepared PE-based ACFs, the isothermal adsorption/desorption curve was measured for each ACF sample. The results are shown in Figure 8. As the amount of nitrogen adsorption increased with an increasing activation time, the pore structure gradually became denser in proportion to the activation time. In addition, hysteresis became more pronounced with an increasing activation time, meaning that mesopores were formed at a slightly higher rate [29]. The isothermal adsorption/desorption curve of PE-based ACFs had the shape of Type-I based on the IUPAC classification. It was assumed that micropores were typically well-developed. However, near the relative pressure of about $0.05 \mathrm{P} / \mathrm{P}_{0}$, the slope of the isothermal adsorption/desorption curve decreased rapidly. It was determined that a significant portion of mesopores was included.

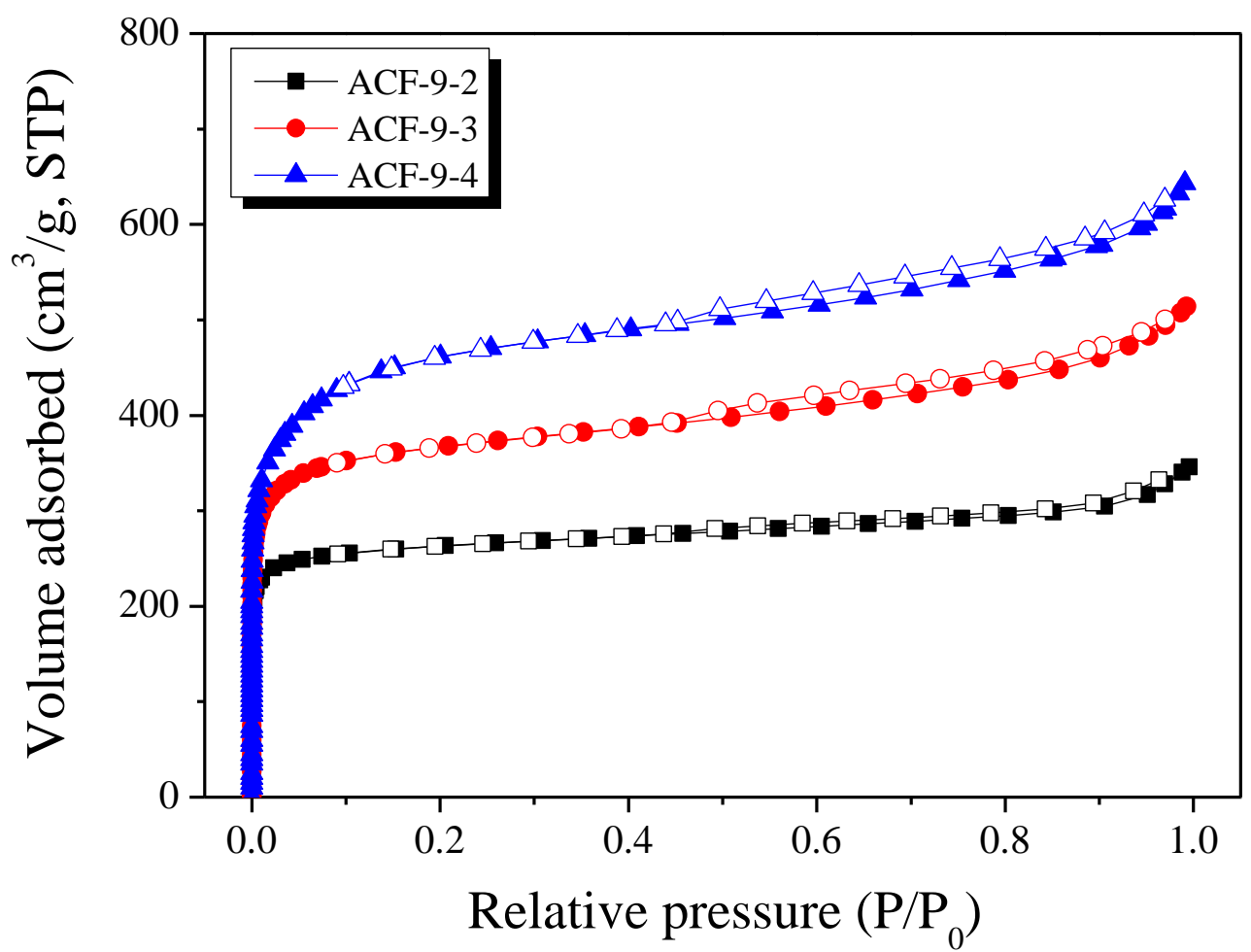

Figure 8. $\mathrm{N}_{2} / 77 \mathrm{~K}$ adsorption/desorption isotherms of LLDPE-based activated carbon fibers as a function of activation time.

The textural properties of all ACF samples are summarized in Table 4 . The specific surface area and total pore volume of PE-based ACFs were observed to be $1040 \sim 1750 \mathrm{~m}^{2} / \mathrm{g}$ and $0.53 \sim 0.99 \mathrm{~cm}^{3} / \mathrm{g}$, respectively. The volumes of micropores and mesopores also increased as the activation time increased. It was confirmed that the mesopores' volume $\left(0.16 \sim 0.39 \mathrm{~cm}^{3} / \mathrm{g}\right)$ accounted for $30-39 \%$ of the total pore volume. This indicated that many mesopores appeared during the further activation process, which meant that many closed mesopores had already been generated by the oxidation of small crystallites during carbonization or activation. In addition, it was believed that the pore structure of ACFs could be controlled by controlling the crosslinking process. Such ACFs developed with controlled pore structures are expected to be suitable for use in various applications. 
Table 4. Pore characteristics of activated carbon fibers based on LLDPE manufactured with different activation times.

\begin{tabular}{cccccc}
\hline Sample Name & $\mathbf{S}_{\text {BET }}\left(\mathbf{m}^{\mathbf{2}} / \mathbf{g}\right)$ & $\begin{array}{c}\mathbf{V}_{\text {Total }} \\
\left(\mathbf{c m}^{\mathbf{3}} / \mathbf{g}\right)\end{array}$ & $\begin{array}{c}\mathbf{V}_{\text {Micro }} \\
\left.\mathbf{( c m}^{3} / \mathbf{g}\right)\end{array}$ & $\begin{array}{c}\mathbf{V}_{\text {Meso }} \\
\left(\mathbf{c m}^{\mathbf{3}} / \mathbf{g}\right)\end{array}$ & Yield (\%) \\
\hline ACF-9-2 & 1040 & 0.53 & 0.37 & 0.16 & 55.2 \\
ACF-9-3 & 1420 & 0.79 & 0.49 & 0.30 & 36.4 \\
ACF-9-4 & 1750 & 0.99 & 0.60 & 0.39 & 10.0 \\
\hline
\end{tabular}

The micropore and mesopore size distribution curves of PE-based ACFs were observed using NLDFT and BJH, respectively. The results are shown in Figure 9. The micropore distribution curves of PE-based ACFs revealed that ACF-9-2 mainly had over $1 \mathrm{~nm}$ of micropores and over $2 \mathrm{~nm}$ of mesopores. This is different from commercial ACFs, which generally have only well-developed micropores. In addition, it was observed that the distribution curve of micropores widened as the activation time increased. In the case of the mesopore distribution curve, it was confirmed that mesopores were well-developed within a wide range from 2 to $100 \mathrm{~nm}$ in all PE-based ACFs. It was also confirmed that the pore volume with such a range steadily increased with an increasing activation time. The above results concluded that PE-based ACF had both micropores (from the oxidation of amorphous and crystallite edges) and mesopores (from the oxidation of small crystallites resulting from the crosslinking process).
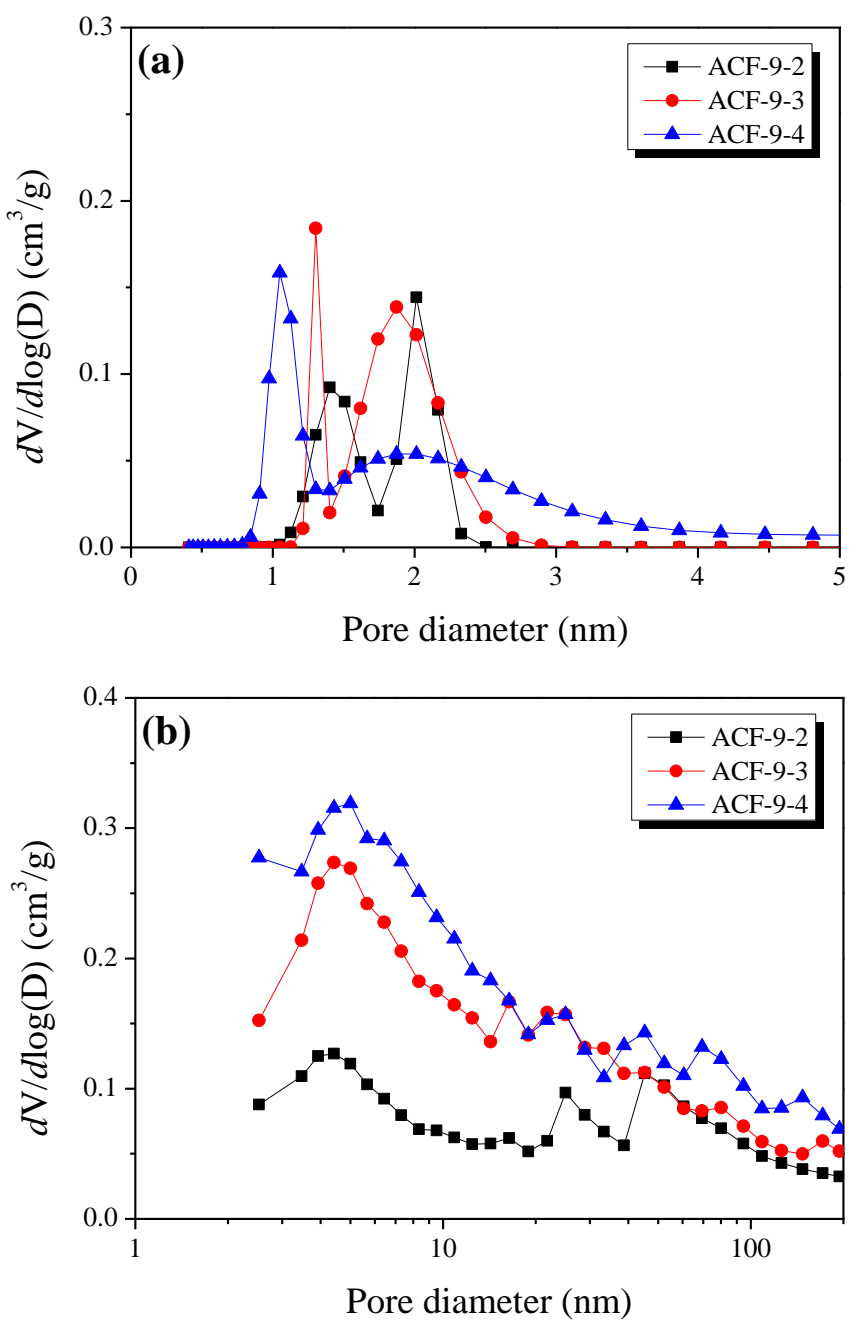

Figure 9. Pore size distribution curves of LLDPE-based activated carbon fibers as a function of activation time: (a) micropore, (b) mesopore. 
The adsorption behaviors of the ACF for harmful gases were observed by measuring the acetaldehyde breakthrough curves. Figure 8 exhibits the breakthrough curves of PEbased ACF and commercial ACF (FM10 was selected as a comparative sample, a cellulosebased activated carbon fiber from Chemviron from the UK. FM10 has a $1180 \mathrm{~m}^{2} / \mathrm{g}$ specific surface area, $0.5 \mathrm{~cm}^{3} / \mathrm{g}$ total pore volume, and $0.44 \mathrm{~cm}^{3} / \mathrm{g}$ micropore volume).

PE-based ACF exhibited a longer breakthrough time than FM10 but a shorter saturation time (Table 5 and Figure 10). The acetaldehyde adsorption capacity of ACF-9-4 was $1.27 \mathrm{mg} / \mathrm{g}$, which was observed to be about $164 \%$ of the acetaldehyde adsorption capacity of FM10. On the other hand, FM10 has more breakthrough capacity because the slope of the breakthrough curve is lower than that of ACF-9-4. In many previous studies, the acetaldehyde adsorption capacity was found to be highly correlated with the micropore volume of the adsorbent [30]. The values obtained by dividing the adsorption capacity by each micropore volume were confirmed to be 2.12 and 1.75 , respectively. This means that the micropore volume is not the only factor determining the acetaldehyde adsorption capacity of the ACFs, but that the nature of the precursor or manufacturing can also affect their adsorption ability. Therefore, ACF-9-4 is considered to have a higher acetaldehyde adsorption performance than FM10 because it has an advanced porous structure and material characteristics.

Table 5. Breakthrough and saturation adsorption capacity of the LLDPE-based activated carbon fibers.

\begin{tabular}{|c|c|c|c|c|c|}
\hline \multirow[b]{2}{*}{ Gas } & \multicolumn{3}{|c|}{ Breakthrough } & \multicolumn{2}{|c|}{ Saturation } \\
\hline & Time (min) & $\begin{array}{c}\text { Adsorption } \\
\text { Capacity (mg/g) }\end{array}$ & $\begin{array}{c}\text { Adsorption } \\
\text { Capacity/Micropore } \\
\text { Volume }\left(\mathrm{mg} / \mathrm{cm}^{3}\right)\end{array}$ & Time (min) & $\begin{array}{c}\text { Adsorption } \\
\text { Capacity (mg/g) }\end{array}$ \\
\hline ACF-9-4 & 16.2 & 1.27 & 2.12 & 42.5 & 1.98 \\
\hline FM10 & 10.0 & 0.77 & 1.75 & 55.1 & 2.20 \\
\hline
\end{tabular}

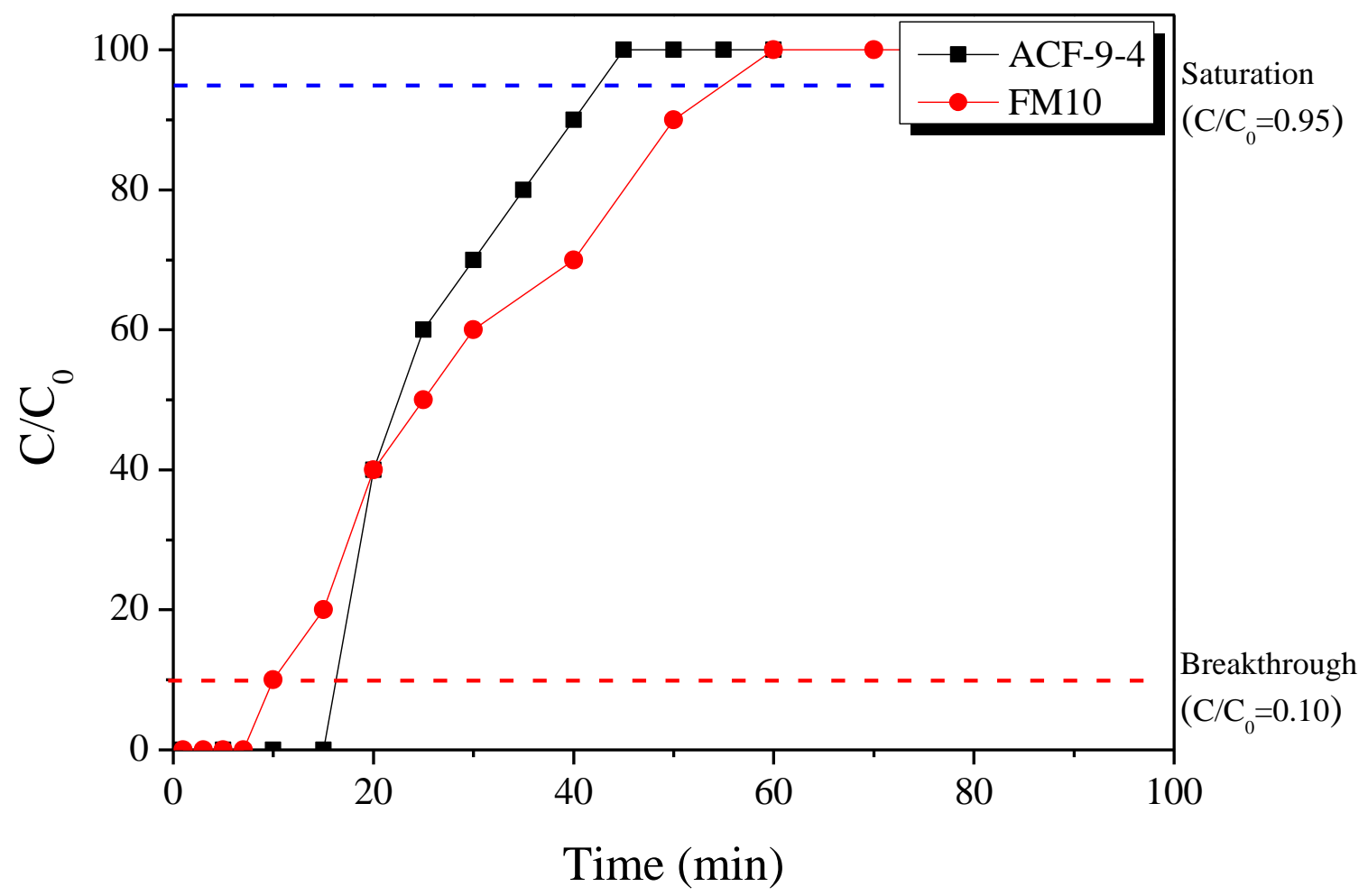

Figure 10. Breakthrough curves for the acetaldehyde adsorption of LLDPE-based activated carbon fibers. 


\section{Conclusions}

In this study, linear low-density polyethylene (LLDPE)-derived activated carbon fibers (PE-ACF) were prepared by techniques of crosslinking, carbonization, and subsequent steam activation under various conditions. The LLDPE as a precursor was crosslinked by a hybrid process to obtain a high degree of carbonization. The total pore volume and specific surface area of the activated samples increased with a longer activation time to final values of $0.99 \mathrm{~cm}^{3} / \mathrm{g}$ and $1750 \mathrm{~m}^{2} / \mathrm{g}$, respectively. The PE-ACF also exhibited a high mesopore volume ratio of $39 \%$. The structural characteristics of the precursor LLDPE led to the production of ACFs with a mesopore-rich pore structure. The prepared PE-ACFs were confirmed to have better pore characteristics and aldehyde adsorption properties than the conventional commercial ACF. These results indicate that LLDPE can be a potential material for preparing activated carbon fiber precursors and that hybrid crosslinking shows potential for the development of PE-based carbon fibers.

Author Contributions: Data curation, S.-H.K.; Formal analysis, H.-M.L.; Methodology, B.-J.K.; Project administration, B.-J.K.; Writing—original draft, K.-W.K.; Writing—review \& editing, B.-J.K. All authors have read and agreed to the published version of the manuscript.

Funding: This research was funded by Nano-Material Technology Development Program through the National Research Foundation of Korea (NRF) funded by the Ministry of Science and ICT (NRF-2019M3A7B9071501).

Institutional Review Board Statement: Not applicable.

Informed Consent Statement: Not applicable.

Data Availability Statement: Not applicable.

Acknowledgments: This research was supported by the Nano-Material Technology Development Program through the National Research Foundation of Korea (NRF) funded by the Ministry of Science and ICT (NRF-2019M3A7B9071501).

Conflicts of Interest: The authors declare no conflict of interest.

\section{References}

1. Suzuki, M. Activated carbon fiber: Fundamentals and applications. Carbon 1994, 32, 577-586. [CrossRef]

2. Ko, T.-H.; Chiranairadul, P.; Lu, C.-K.; Lin, C.-H. The effects of activation by carbon dioxide on the mechanical properties and structure of PAN-based activated carbon fibers. Carbon 1992, 30, 647-655. [CrossRef]

3. Lee, H.M.; Kim, H.G.; Kang, S.J.; Park, S.J.; An, K.H.; Kim, B.J. Effects of pore structures on electrochemical behaviors of polyacrylonitrile (PAN)-based activated carbon nanofibers. J. Ind. Eng. Chem. 2015, 21, 736-740. [CrossRef]

4. Derbyshire, F.; Andrews, R.; Jacques, D.; Jagtoyen, M.; Kimber, G.; Rantell, T. Synthesis of isotropic carbon fibers and activated carbon fibers from pitch precursors. Fuel 2001, 80, 345-356. [CrossRef]

5. Hina, K.; Zou, H.; Qian, W.; Zuo, D.; Yi, C. Preparation and performance comparison of cellulose-based activated carbon fibres. Cellulose 2018, 25, 607-617. [CrossRef]

6. Yusof, N.; Ismail, A.F. Post spinning and pyrolysis processes of polyacrylonitrile (PAN)-based carbon fiber and activated carbon fiber: A review. J. Anal. Appl. Pyrolysis 2012, 93, 1-13. [CrossRef]

7. Teng, H.; Wang, S.C. Preparation of porous carbons from phenol-Formaldehyde resins. Carbon 2000, 38, 817-824. [CrossRef]

8. Williams, P.; Reed, A. Development of activated carbon pore structure via physical and chemical activation of biomass fibre waste. Biomass Bioenergy 2006, 30, 144-152. [CrossRef]

9. Gbewonyo, S.; Xiu, S.; Shahbazi, A.; Zhang, L. Low thermal conductivity carbon material from electrospinning and subsequent chemical activation. Carbon Lett. 2020, 30, 289-296. [CrossRef]

10. Maciá-Agulló, J.A.; Moore, B.C.; Cazorla-Amorós, D.; Linares-Solano, A. Activation of coal tar pitch carbon fibres: Physical activation vs. chemical activation. Carbon 2004, 42, 1367-1370. [CrossRef]

11. Kim, M.I.; Im, J.S.; Cho, J.H.; Lee, Y.S.; Kim, S. Preparation of pitch-based activated carbon with surface-treated fyash for $\mathrm{SO}_{2}$ gas removal. Carbon Lett. 2020, 30, 381-387. [CrossRef]

12. Kim, B.K.; Ryu, S.K.; Kim, B.J.; Park, S.J. Roles of acid-base interactions in hydrogen chloride removal by activated carbon fibers. J. Ind. Eng. Chem. 2006, 12, 121-126.

13. Kim, M.-J.; Kim, K.H.; Kim, Y.; Yoo, B.; Lee, Y.-S. Volatile organic compounds (VOCs) removal using ACFs with electroless plating $\mathrm{CuO}$ as catalysts. Carbon Lett. 2020, 30, 675-682. [CrossRef] 
14. Lee, H.-M.; Kim, K.-W.; Park, Y.-K.; An, K.-H.; Park, S.-J.; Kim, B.-J. Activated Carbons from Thermoplastic Precursors and Their Energy Storage Applications. Nanomaterials 2019, 9, 896. [CrossRef] [PubMed]

15. Hassan, M.F.; Sabri, M.A.; Fazal, H.; Hafeez, A.; Shezad, N.; Hussain, M. Recent trends in activated carbon fibers production from various precursors and applications-A comparative review. J. Anal. Appl. Pyrolysis 2020, 145, 104715. [CrossRef]

16. Yahya, M.A.; Al-Qodah, Z.; Ngah, C.W.Z. Agricultural bio-waste materials as potential sustainable precursors used for activated carbon production: A review. Renew. Sustain. Energy Rev. 2015, 46, 218-235. [CrossRef]

17. Wortberg, G.; De Palmenaer, A.; Beckers, M.; Seide, G.; Gries, T. Polyethylene-Based Carbon Fibers by the Use of Sulphonation for Stabilization. Fibers 2015, 3, 373-379. [CrossRef]

18. Kim, K.W.; Lee, H.M.; Kim, B.S.; Hwang, S.H.; Kwac, L.K.; An, K.H.; Kim, B.J. Preparation and thermal properties of polyethylenebased carbonized fibers. Carbon Lett. 2015, 16, 62-66. [CrossRef]

19. Tretinnikov, O.N.; Ogata, S.; Ikada, Y. Surface crosslinking of polyethylene by electron beam irradiation in air. Polymer 1998, 39, 6115-6120. [CrossRef]

20. Bremner, T.; Rudin, A. Peroxide modification of linear low-density polyethylene: A comparison of dialkyl peroxides. J. Appl. Polym. Sci. 1993, 49, 785-798. [CrossRef]

21. Azizi, H.; Barzin, J.; Morshedian, J. Silane crosslinking of polyethylene: The effects of EVA, ATH and $\mathrm{Sb}_{2} \mathrm{O}_{3}$ on properties of the production in continuous grafting of LDPE. Express Polym. Lett. 2007, 1, 378-384. [CrossRef]

22. Li, C.; Zhu, H.; Salim, N.V.; Fox, B.L.; Hameed, N. Preparation of microporous carbon materials via in-depth sulfonation and stabilization of polyethylene. Polym. Degrad. Stab. 2016, 134, 272-283. [CrossRef]

23. Liu, S.-Q.; Gong, W.-G.; Zheng, B.-C. The Effect of Peroxide Cross-Linking on the Properties of Low-Density Polyethylene. J. Macromol. Sci. Phys. 2014, 53, 67-77. [CrossRef]

24. Kim, M.J.; Song, E.J.; Kim, K.H.; Choi, S.S.; Lee, Y.-S. The textural and chemical changes in ACFs with E-beam and their influence on the detection of nerve agent simulant gases. J. Ind. Eng. Chem. 2019, 79, 465-472. [CrossRef]

25. Kang, S.-H.; Kim, K.-W.; Kim, B.-J. Carbon Fibers from High-Density Polyethylene Using a Hybrid Cross-Linking Technique. Polymers 2021, 13, 2157. [CrossRef]

26. Brunauer, S.; Emmett, P.H.; Teller, E. Adsorption of Gases in Multimolecular Layers. J. Am. Chem. Soc. 1938, 60, 309-319. [CrossRef]

27. Kierlik, E.; Rosinberg, M.L. Free-energy density functional for the inhomogeneous hard-sphere fluid: Application to interfacial adsorption. Phys. Rev. A 1990, 42, 3382-3387. [CrossRef] [PubMed]

28. Barrett, E.P.; Joyner, L.G.; Halenda, P.P. The Determination of Pore Volume and Area Distributions in Porous Substances. I. Computations from Nitrogen Isotherms. J. Am. Chem. Soc. 1951, 73, 373-380. [CrossRef]

29. Lee, H.-M.; Lee, B.-H.; Kim, J.-H.; An, K.-H.; Park, S.-J.; Kim, B.-J. Determination of the optimum porosity for 2-CEES adsorption by activated carbon fiber from various precursors. Carbon Lett. 2019, 29, 649-654. [CrossRef]

30. Wang, H.; Zhu, T.; Fan, X.; Na, H. Adsorption and desorption of small molecule volatile organic compounds over carbide-derived carbon. Carbon 2014, 67, 712-720. [CrossRef] 